\title{
B Chromosome Variants of the Grasshopper Xyleus discoideus angulatus Are Potentially Derived from Pericentromeric DNA
}

\author{
Andrezza C.S. Bernardino ${ }^{a}$ Diogo C. Cabral-de-Mello ${ }^{b}$ Carolina B. Machado ${ }^{c}$ \\ Octavio M. Palacios-Gimenez ${ }^{\mathrm{b}}$ Neide Santos ${ }^{\mathrm{a}}$ Vilma Loreto $^{\mathrm{a}}$ \\ aDepartamento de Genética, Centro de Biociências, Universidade Federal de Pernambuco (UFPE), Recife, \\ ${ }^{b}$ Departamento de Biologia, Instituto de Biociências, Universidade Estadual Paulista (Unesp), Rio Claro, and \\ 'Departamento de Genética e Evolução, Universidade Federal de São Carlos (UFSCar), São Carlos, Brazil
}

\section{Keywords}

$\mathrm{C}_{0} \mathrm{t}-\mathrm{DNA} \cdot$ Evolution $\cdot \mathrm{FISH} \cdot \mathrm{Microdissection} \cdot$ Population

\begin{abstract}
B chromosomes, extra elements present in the karyotypes of some eukaryote species, have been described in the grasshopper Xyleus discoideus angulatus. Although some studies have proposed an autosomal origin of the $B$ chromosome in $X$. d. angulatus, little is known about its repetitive DNA composition and evolutionary dynamics. The aim of the present work was to shed light on the B chromosome evolution in $X$. d. angulatus by cytogenetic analysis of 27 populations from Pernambuco and Ceará states (Brazil). The frequency of $B$ chromosomes in the different populations was determined, and chromosome measurements and fluorescence in situ hybridization (FISH) with $\mathrm{C}_{0}$ t-DNA and telomeric and B chromosome sequences were performed in cells from B-carrying individuals. The results revealed variations in $\mathrm{B}$ chromosome prevalence among the populations and showed that some $\mathrm{B}$ chromosomes were smaller in certain populations. FISH produced similar patterns for the $C_{0}$ t-DNA probe in all hybridized individuals, whereas telomeric and $B$ chromosome probes, obtained by microdissection, exhibited variations in their distribution. These results indicate the presence of 3
\end{abstract}

\section{KARGER}

(C) 2017 S. Karger AG, Basel

E-Mail karger@karger.com

www.karger.com/cgr morphotypes of B chromosomes in X. d. angulatus, with variation in repetitive DNA composition during their evolution. In this species, B chromosomes have an intraspecific origin and probably arose from the pericentromeric region of $A$ chromosomes.

(c) 2017 S. Karger AG, Basel

B chromosomes, also denominated supernumerary or accessory chromosomes, are extra dispensable elements found in the karyotypes of about $15 \%$ of eukaryote species. These elements are enriched in repetitive DNAs such as multigene families, satellite DNA, and mobile elements [Camacho, 2005; Houben et al., 2013, 2014], although recent studies also evidenced B chromosomes carrying protein-coding sequences and functional ribosomal DNA (rDNA) [Ruíz-Estévez et al., 2012, 2013; Banaei-Moghaddam et al., 2013, 2015; Trifonov et al., 2013; Valente et al., 2014]. Frequently new variants of B chromosomes arise, and a high mutation capacity seems to persist in the genome. Several molecular processes occur more rapidly in B chromosomes than in A chromosomes (e.g., heterochromatinization and accumulation of various transposable elements) [Camacho et al., 2000; Houben et al., 2013, 2014]. Moreover, supernumerary elements present dif-

Vilma Loreto

Departamento de Genética, Centro de Biociências Universidade Federal de Pernambuco (UFPE)

Recife, PE 50740-600 (Brazil)

E-Mail vloreto@ bol.com.br 


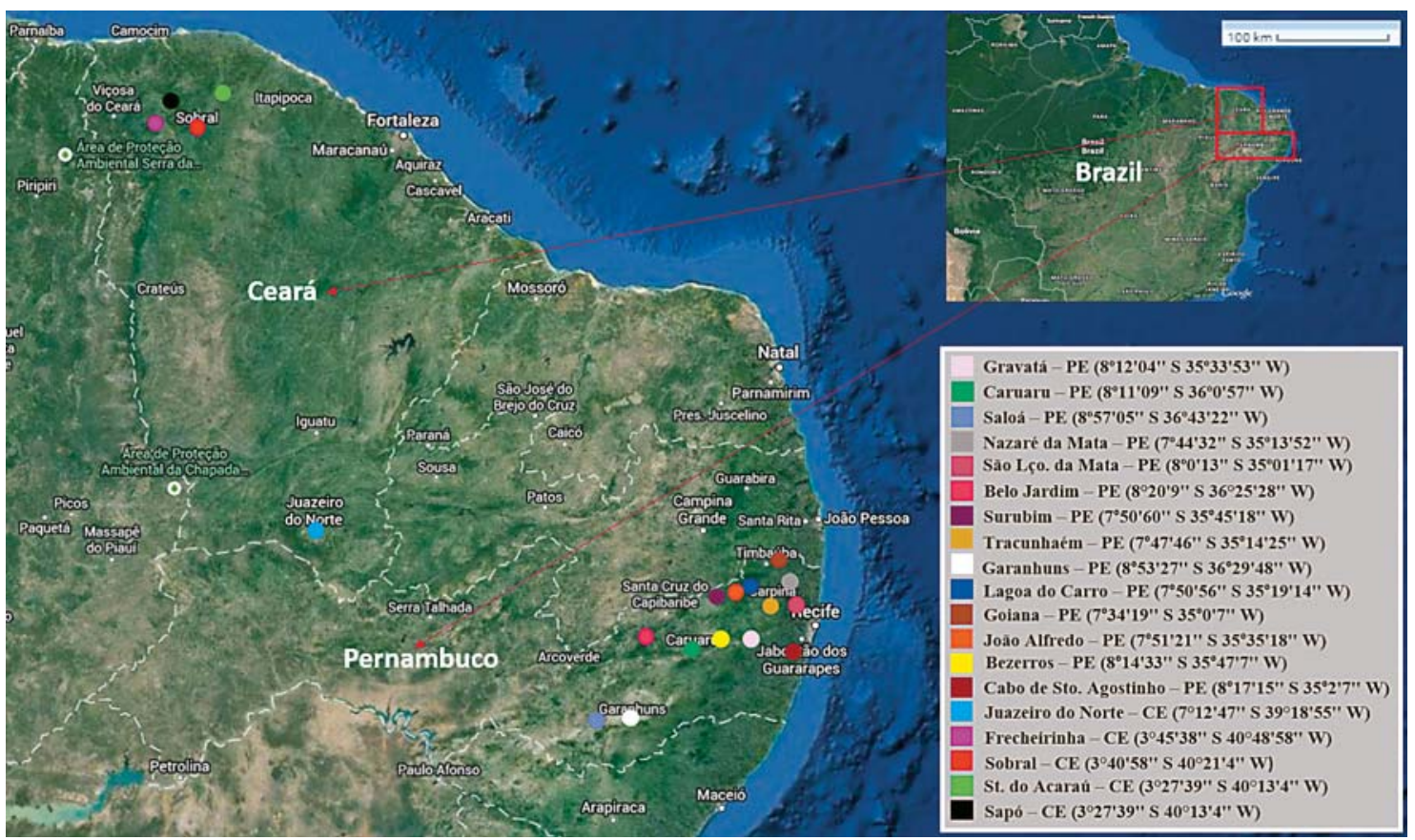

Fig. 1. Map showing the collecting sites of Xyleus discoideus angulatus in the states of Pernambuco and Ceará, Brazil. Lço, Lourenço; Sto, Santo. Source, Google Maps.

ferent compositions and morphological characteristics that vary according to their intra- or interspecific origin [Camacho et al., 2000].

Among grasshoppers, species possessing distinct B variants were reported, for example Eyprepocnemis plorans, in which more than $50 \mathrm{~B}$ chromosome variants have been described, with a broad range of morphological and molecular composition [Hewitt, 1979; HenriquesGil et al., 1984; López-León et al., 1994; Teruel et al., 2009a]. However, other species exhibit a few different B morphotypes, such as Podisma sapporensis sapporensis, which presents distinct patterns of C-bands, and A and $\mathrm{B}$ chromosome probes hybridize on its $\mathrm{B}$ chromosomes [Warchalowska-Sliwa et al., 2001; Bugrov et al., 2004].

Most studies of $\mathrm{B}$ chromosomes in grasshoppers were performed in species from the family Acrididae, such as Euplectrotettix shultzi and E. conspersus [Vilardi, 1986a], E. plorans [Hewitt, 1979], Locusta migratoria [Cabrero et al., 1984; Teruel et al., 2009b], Rhammatocerus brasiliensis [Loreto et al., 2008], Abracris flavolineata [Bueno et al., 2013], and Dichroplus pratensis [Bidau and Martí, 2004]. However, in the family Romaleidae, B chromosomes are restricted to Zoniopoda tarsata [Vilardi, 1986b] and Xyleus discoideus angulatus [Souza and Kido, 1995; Loreto et al., 2008; Machado et al., 2014].
$X . d$. angulatus presents a diploid chromosome number of $2 \mathrm{n}=23, \mathrm{X} 0 / 24, \mathrm{XX}$ and acrocentric chromosomes [Souza and Silva-Filha, 1993]. Additionally, an acrocentric B chromosome was reported in some populations [Souza and Kido, 1995; Machado et al., 2014]. The first study involving the B chromosome in this species described it as a numerically unstable element in females, with a size, morphology, and heterochromatic nature similar to the X [Souza and Kido, 1995]. An autosomal origin has been proposed for the B chromosome in $X . d$. angulatus based on its prevalence in different populations in Pernambuco (Brazil) and the distribution patterns of $18 \mathrm{~S}$ rRNA and $\mathrm{H} 4$ histone genes [Loreto et al., 2008; Machado et al., 2014].

In order to better understand the evolutionary dynamics of B chromosomes in the grasshopper $X$. $d$. angulatus at the population level, we performed chromosome analyses in individuals sampled in 27 populations from Pernambuco and Ceará states, Brazil. B chromosome prevalence, morphology, and size variation were investigated. Moreover the telomeric repeat (TTAGG) $)_{\mathrm{n}}$, a highly and moderately repetitive DNA fraction $\left(\mathrm{C}_{0} \mathrm{t}-\mathrm{DNA}\right)$, and the microdissected $\mathrm{B}$ chromosome were used as probes to highlight the composition and diversification of the $\mathrm{B}$ chromosome in distinct populations. 


\section{Materials and Methods}

Material Collection, Chromosome Preparation, and

B Chromosome Analysis

A total of 706 male individuals of $X$. d. angulatus were collected from 2004 to 2014 at 14 and 5 distinct localities in Pernambuco (PE) and Ceará (CE) states, respectively, Northeast of Brazil (Fig. 1; Table 2). In order to compare the B chromosome frequency in different years and populations, data on $\mathrm{B}$ chromosome prevalence previously published by Machado et al. [2014] were included in the analysis. Thus, B chromosome prevalence in a total of 19 localities divided into 27 populations was analyzed (see Table 2 for details). All individuals were anesthetized with ether for gonad removal, and the testes were fixed in Carnoy solution (3:1 ethanol:acetic acid). Some individuals were stored at $-20^{\circ} \mathrm{C}$ for genomic DNA extraction.

Slides were prepared by the classical squashing technique of testicular follicles. For conventional analysis, the chromosomes were stained with $2 \%$ lacto-acetic orcein for $5 \mathrm{~min}$. The cytological preparations were analyzed by chromosome counting, and the presence or absence of $\mathrm{B}$ chromosomes was verified in at least 5 meiotic cells of each individual. Chromosome preparations for FISH were obtained through maceration of the material in 1 drop of $50 \%$ acetic acid. Subsequently, evaporation of the acetic acid was induced using a hot plate with temperatures between 40 and $45^{\circ} \mathrm{C}$.

Statistical analysis was performed using at first the test of Shapiro-Wilk with $\alpha=0.05$ to verify whether the samples had a normal distribution. Then, the Mann-Whitney test with $\alpha=0.05$ was applied to verify whether there was significant difference between the prevalence rates of $\mathrm{B}$ chromosomes and the different environments where the specimens were collected (Atlantic Forest and Caatinga).

\section{Chromosome Measurements}

$\mathrm{X}$ and $\mathrm{B}$ chromosomes were measured in a total of 240 cells from 24 individuals of $X$. $d$. angulatus (10 cells per individual); 5 of them were collected in Bezerros (PE), 5 in Lagoa do Carro (PE), 1 in Gravatá (PE), 10 in Juazeiro do Norte (CE), 1 in Sapó (CE), 1 in Frecheirinha (CE), and 1 in Sobral (CE) (Table 1). Populations were selected according to the availability criterion. In Pernambuco, those with a higher number of specimens containing B chromosomes were used for analysis. In Ceará, measurements were carried out in individuals from all localities in which a B chromosome was found.

The X chromosome was selected for size comparison with the $\mathrm{B}$ chromosome, owing to the fact that both show a similar behavior during meiosis. Thus, $\mathrm{X}$ and $\mathrm{B}$ chromosomes are both univalents and have comparable condensation levels. This analysis was performed to evaluate interindividual differences for B chromosomes, since the $\mathrm{X}$ chromosome is shared between all individuals. Chromosomes were measured using the Image J program, considering a scale of $5 \mu \mathrm{m}$ that was attributed to image. B and X chromosomes were measured in each cell, and the $\mathrm{B} / \mathrm{X}$ ratio was calculated in order to evaluate differences in B chromosome size between the individuals. The analyses were conducted for each individual separately and then after combining all individuals from Pernambuco and all from Ceará in 2 distinct groups. Statistical analysis was performed first using the Shapiro-Wilk test with $\alpha=0.05$ to verify whether the samples had a normal distribution, and, if so, Student $t$ test, also with $\alpha=0.05$, to determine whether the difference of mean values between Ceará and Pernambuco was significant.

B Chromosome Variants in the

Grasshopper X. d. angulatus
Table 1. B/X ratios determined in Xyleus discoideus angulatus individuals from populations in Pernambuco and Ceará

\begin{tabular}{lll}
\hline Population & Individual & Mean B/X ratio \\
\hline Pernambuco & & \\
Bezerros & 1 & 0.79 \\
& 2 & 0.87 \\
& 3 & 0.78 \\
& $4^{\mathrm{a}}$ & 0.76 \\
Lagoa do Carro & 5 & 0.78 \\
& $6^{\mathrm{a}}$ & 0.64 \\
& 7 & 0.86 \\
& 8 & 0.83 \\
Gravatá & 9 & 0.84 \\
\hline Overall average & 10 & 0.87 \\
\hline Ceará & $11^{\mathrm{a}}$ & 0.77 \\
Juazeiro do Norte (2007) & - & 0.80 \\
& $12^{\mathrm{a}}$ & \\
& 13 & 0.64 \\
Frecheirinha & 14 & 0.66 \\
Sobral & 15 & 0.69 \\
Overall average & 16 & 0.59 \\
Juazeiro do Norte (2011/2013) & 17 & 0.67 \\
& 18 & 0.69 \\
& $19^{\mathrm{a}}$ & 0.61 \\
& 20 & 0.70 \\
& 21 & 0.72 \\
& $22^{\mathrm{a}}$ & 0.68 \\
& $23^{\mathrm{a}}$ & 0.59 \\
& $24^{\mathrm{a}}$ & 0.93 \\
& - & 0.80 \\
\hline & & 0.69 \\
& & \\
& & \\
& & \\
& & \\
& & \\
& & \\
& & \\
& & \\
& & \\
& &
\end{tabular}

${ }^{\text {a }}$ In these individuals, FISH with $\mathrm{C}_{0} \mathrm{t}-1 \mathrm{DNA}$, telomeric, and B chromosome probe was performed.

\section{Preparation of $C_{0} t-D N A$, Telomeric, and B Chromosome}

Probes

Samples enriched with repetitive DNA of $X$. $d$. angulatus were obtained based on kinetic renaturation of $\mathrm{C}_{0} \mathrm{t}$-DNA (DNA enriched with moderately and highly repetitive DNA sequences) according to the protocol described by Zwick et al. [1997], with modifications of Cabral-de-Mello et al. [2010]. Genomic DNA from an individual without a B chromosome from Gravatá (PE) was used in this assay. The reannealing time was $25 \mathrm{~min}$. Telomeric probes were obtained via PCR, in the absence of template, using the selfcomplementary primers (TTAGG) $)_{5}$ and (CCTAA) $)_{5}$ following the protocol of Ijdo et al. [1991].

For B chromosome microdissection, a suspension of testicular cells from 1 individual from Gravatá (PE) harboring 1 B chromosome was prepared. Testicular follicles were macerated in a microtube containing $40 \mu \mathrm{L}$ of $50 \%$ acetic acid. Subsequently, the suspension was dropped onto a $24 \times 60 \mathrm{~mm}$ coverslip and stained with $5 \%$ Giemsa for $5 \mathrm{~min}$. On the next day, microdissection was carried out using an Eppendorf 5171 micromanipulator coupled with a

Cytogenet Genome Res 2017;152:213-221 
Zeiss Axiovert 40 CFL inverted microscope. Ten B chromosomes were microdissected and stored in 1 microtube containing $9 \mu \mathrm{L}$ of ultrapure water. DNA of the microdissected chromosomes was amplified using the GenomePlex Single Cell Whole Genome Amplification WGA4 kit (Sigma-Aldrich, St Louis, MO, USA) followed by reamplification using the GenomePlex WGA3 kit (Sigma-Aldrich). The reaction product was visualized in a $1 \%$ agarose gel and used to generate the B chromosome probe by DNA amplification with the GenomePlex WGA3 kit.

Fluorescence in situ Hybridization

The telomere probe was labeled by PCR using digoxigenin11-dUTP (Roche, Mannheim, Germany) during the synthesis. $\mathrm{C}_{0} \mathrm{t}-\mathrm{DNA}$ and the microdissected $\mathrm{B}$ chromosome were labeled via nick translation using biotin-14-dATP (Invitrogen, San Diego, CA, USA) and digoxigenin-11-dUTP, respectively. FISH was performed according to Pinkel et al. [1986], with some modifications of Cabral-de-Mello et al. [2010], and applied to 8 individuals harboring B chromosomes, from 8 different populations: 3 from Pernambuco and 5 from Ceará (Table 1). Double FISH was performed according to Cabrero et al. [2003], and probes labeled with digoxigenin-11-dUTP were detected using rhodamine-conjugated antidigoxigenin (Roche). Probes labeled with biotin-14-dATP were detected using Alexa Fluor 488-conjugated streptavidin (Invitrogen). Chromosomes were counterstained with DAPI and slides mounted in Vectashield (Vector, Burlingame, CA, USA). Images were captured using an Olympus BX61 microscope equipped with appropriate filters and linked to a digital camera DP70 (Olympus). Images were merged and optimized for brightness and contrast using Adobe Photoshop CS5.

\section{Results}

\section{B Chromosome Size and Prevalence}

The B chromosomes observed here were acrocentric, heteropycnotic in relation to autosomes, and varied in size (Fig. 2; Table 1). Side-by-side or end-to-end associations were observed between the $\mathrm{B}$ and $\mathrm{X}$ chromosomes of all populations, with side-by-side associations being common in prophase I. No intraindividual variation in the number of $\mathrm{B}$ chromosomes was observed in the populations from Ceará and Pernambuco (except the specimen described by Machado et al. [2014]), suggesting that it is a mitotically stable element.

Visual inspection revealed that the $\mathrm{B}$ chromosome in $X$. d. angulatus from Ceará (Fig. 2a, b) was smaller than that in individuals from Pernambuco (Fig. 2c, d). In order to confirm the different sizes of the B chromosomes between Ceará and Pernambuco, chromosome measurements were performed in some previously selected populations. The mean values of the $\mathrm{B} / \mathrm{X}$ ratios differed between the populations from Ceará and Pernambuco (Table 1). Considering all populations from Ceará as one sample and those from Pernambuco as another one, the
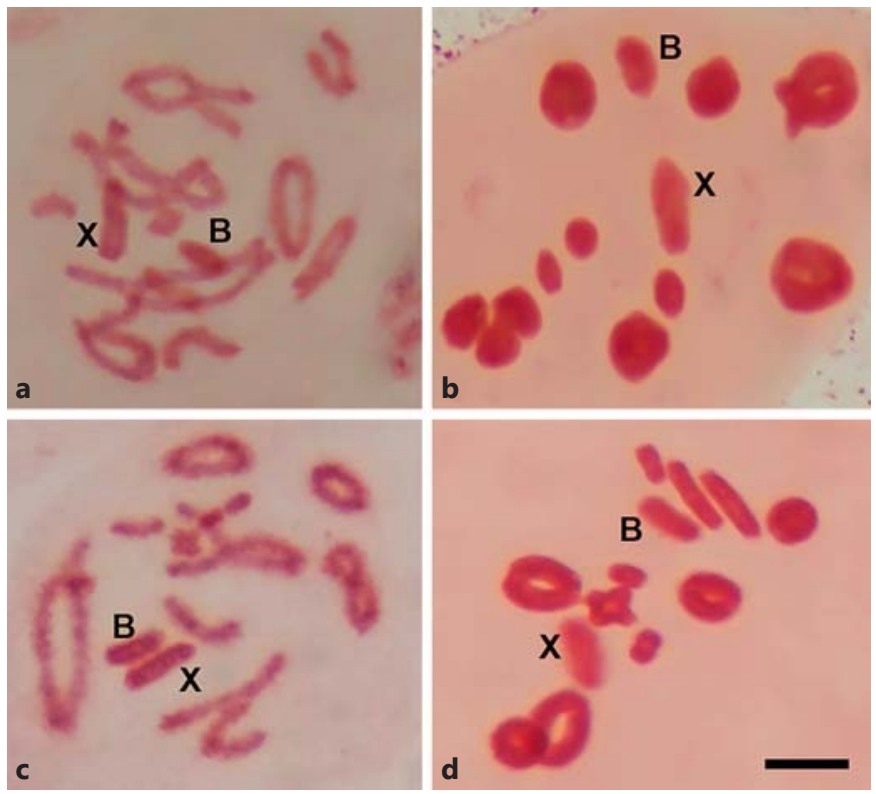

Fig. 2. Conventional analyses in meiotic cells of Xyleus discoideus angulatus individuals with $\mathrm{B}$ chromosomes from Ceará $(\mathbf{a}, \mathbf{b})$ and Pernambuco (c, d). a, c Diplotene cells. b, d Metaphase I cells. Scale bar, $10 \mu \mathrm{m}$.

average $\mathrm{B} / \mathrm{X}$ ratio in Pernambuco was 0.8 and in Ceará 0.69 (Table 1). The Shapiro-Wilk test showed that the samples had a normal distribution $(W=0.9617, p=$ 0.4741 ), allowing the application of Student $t$ test. Significant differences in B chromosome sizes between individuals from Pernambuco and from Ceará were confirmed by the statistical analysis $(t=3.2700, \mathrm{df}=22, p=$ $0.0035)$. Individuals from populations in Ceará presented smaller B chromosomes than those from Pernambuco.

Analyses of B chromosomes performed in 21 populations from Pernambuco, including those analyzed by Machado et al. [2014], and 6 from Ceará revealed 0-2 B chromosomes in the individuals, with a prevalence rate varying from 0 to $44.44 \%$ and a mean value of $10.22 \%$ (Table 2). Eight populations did not present any individual with a B chromosome, 5 populations presented only 1 individual with $1 \mathrm{~B}, 13$ had more than 1 individual with $1 \mathrm{~B}$, and 1 population had only 1 individual with $2 \mathrm{Bs}$. Furthermore, 1 specimen from Lagoa do Carro (PE) analyzed by Machado et al. [2014] presented interfollicular variation of $0-2 \mathrm{~B}$ chromosomes. The Caatinga biome presented the highest $\mathrm{B}$ chromosome occurrence, with a mean of $13.42 \%$, whereas the Atlantic Forest had a mean of $7.02 \%$ (Table 2). The Shapiro-Wilk test showed that the 
Table 2. B chromosome prevalence in 27 Xyleus discoideus angulatus populations in the states of Pernambuco and Ceará (Brazil)

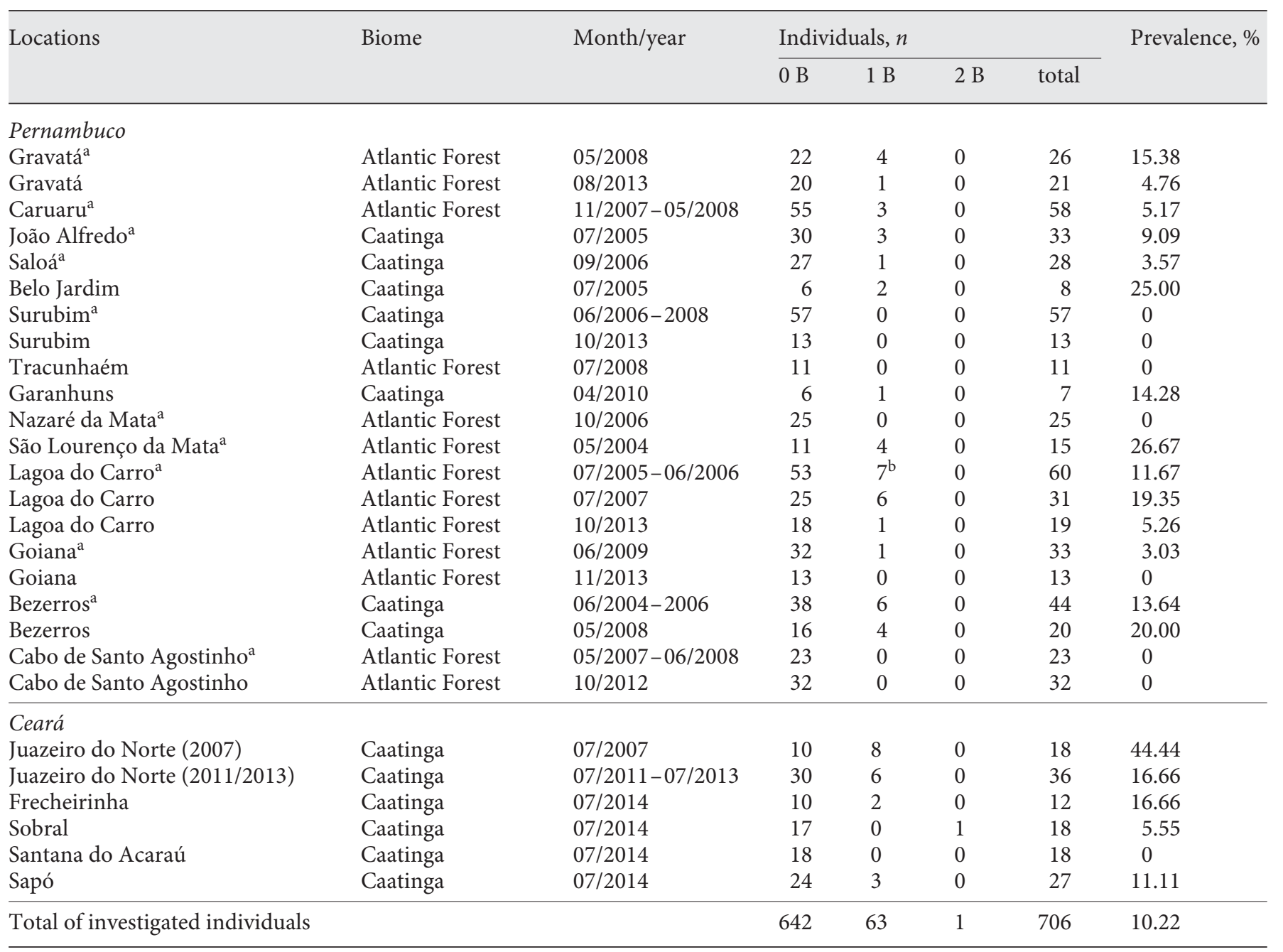

${ }^{a}$ Populations provided by Machado et al. [2014]. ${ }^{\mathrm{b}}$ One individual showed interfollicular variation of 0-2 B chromosomes.

samples had no normal distribution $(W=0.8593, p=$ 0.0095), and statistical analysis by Mann-Whitney, with $a=0.05$, showed no significant difference between prevalence rates of $\mathrm{B}$ chromosomes in the 2 environments where the individuals were sampled $(U=62.50, p=$ 0.1667).

For those localities where sampling was performed in different years and where $\mathrm{B}$ chromosomes were observed (5 localities), variation in B chromosome frequency was noticed. In Gravatá (PE), Goiana (PE), and Juazeiro do Norte (CE), the prevalence decreased, while in Bezerros (PE) it was increased. Finally, in Lagoa do Carro (PE) the prevalence increased from 2005/2006 to 2007 and decreased between 2007 and 2013 (Table 2).

B Chromosome Variants in the Grasshopper X. d. angulatus
Mapping of Repetitive DNAs

FISH using the $\mathrm{C}_{0} \mathrm{t}$-DNA probe obtained from an individual without a $\mathrm{B}$ chromosome in an individual from Gravatá (PE) harboring $1 \mathrm{~B}$ chromosome revealed hybridization signals in the pericentromeric region of all chromosomes of the complement, including the B chromosome. Moreover, a block located in the proximal region of the X chromosome was observed (Fig. 3a). Mapping of telomeric sequences in meiocytes showed them distributed in the centromeric and terminal regions of all chromosomes of the complement (Fig. 3b). In turn, the hybridization of the $\mathrm{B}$ chromosome probe in meiotic cells of 1 specimen from Gravatá (PE) resulted in signals distributed along the entire B. Furthermore, signals in the

Cytogenet Genome Res 2017;152:213-221 DOI: $10.1159 / 000480036$ 

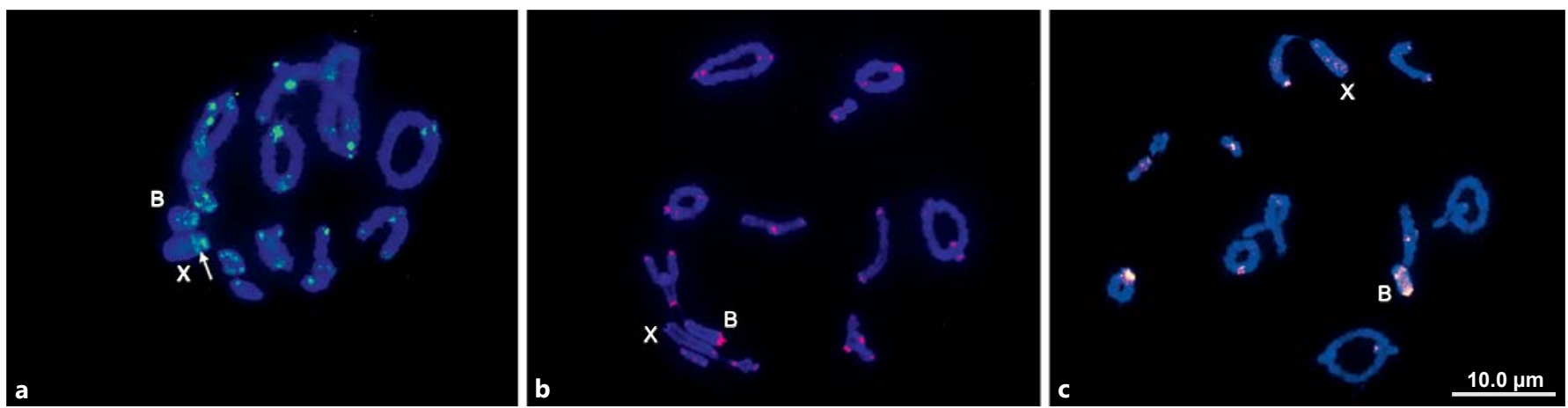

Fig. 3. FISH of $\mathrm{C}_{0} \mathrm{t}-\mathrm{DNA}$ (a), telomeric (b), and B chromosome (c) probes in meiocytes of the grasshopper $X y$ leus discoideus angulatus from Gravatá, PE (a), and Bezerros, PE (b, c), populations. The arrow in a indicates an additional block of $\mathrm{C}_{0} \mathrm{t}$-DNA sequence in the proximal region of the $\mathrm{X}$ chromosome. Scale bar, $10 \mu \mathrm{m}$.

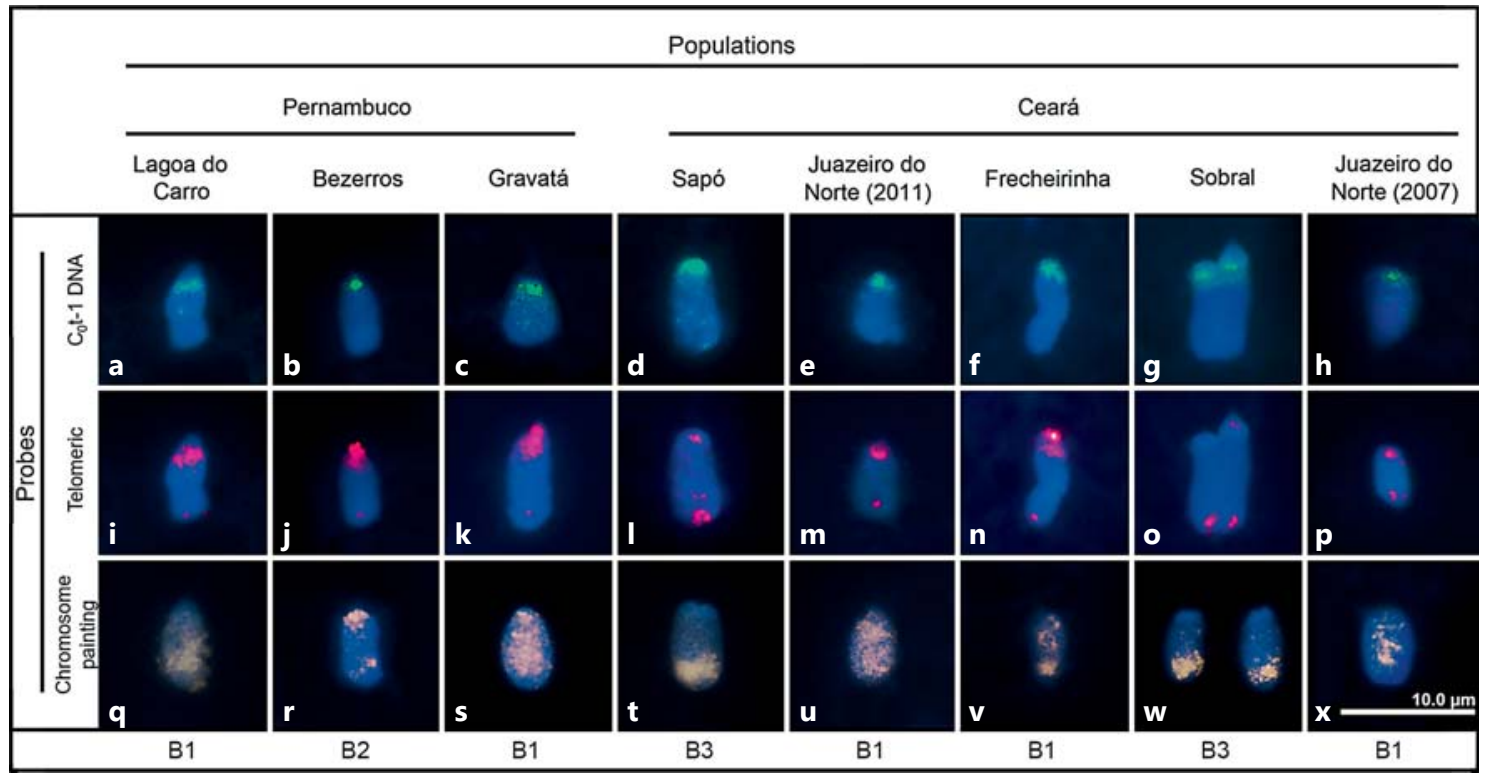

Fig. 4. FISH of $\mathrm{C}_{0} \mathrm{t}-\mathrm{DNA}(\mathbf{a}-\mathbf{h})$, telomeric $(\mathbf{i}-\mathbf{p})$, and $\mathrm{B}$ chromosome (q-x) probes in $\mathrm{B}$ chromosomes obtained from meiocytes of the grasshopper Xyleus discoideus angulatus. Eight populations were analyzed: a, i, q Lagoa do Carro, PE; b, j, r Bezerros, PE; c, k, s Gravatá, PE; d, I, t Sapó, CE; e, m, u Juazeiro do Norte, CE, 2011; f, n, v Frecheirinha, CE; g, o, w Sobral, CE, where the individual analyzed has 2 B chromosomes; $\mathbf{h}, \mathbf{p}, \mathbf{x}$ Juazeiro do Norte, $\mathrm{CE}, 2007$. Note the presence of larger blocks of telomeric DNA in $\mathbf{i}, \mathbf{j}, \mathbf{k}, \mathbf{n}$ and the 3 different morphotypes of $\mathrm{B}$ chromosomes, B1 (q, s, u, v, x), B2 (r), and B3 (t, w). Scale bar, $10 \mu \mathrm{m}$.

pericentromeric regions of some chromosomes of the complement, including the $\mathrm{X}$ chromosome, were present (Fig. 3c).

Physical mapping of the $\mathrm{C}_{0} \mathrm{t}-\mathrm{DNA}$ fraction in $\mathrm{B}$ chromosomes of 3 individuals from Pernambuco and 5 from Ceará revealed similar distribution patterns, with signals restricted to the pericentromeric regions (Fig. $4 \mathrm{a}-\mathrm{h}$ ).
Contrarily, mapping of telomeric DNA sequences produced different patterns. All individuals from the populations of Pernambuco (Lagoa do Carro, Bezerros, and Gravatá) and one of Ceará (Frecheirinha) presented a larger block of telomeric sequences in the short arm of the $\mathrm{B}$ chromosome, occupying the pericentromeric region (Fig. 4i, j, k, n). An individual from 1 population in Ceará 
(Sapó) presented a larger block of telomere repeats in the long arm of the B chromosome (Fig. 41). Individuals from 2 populations in Ceará (Sobral and Juazeiro 2007) did not possess large telomeric blocks as the other populations, but they displayed signals with similar size in both terminal regions of their B chromosomes (Fig. 4o, p). In 1 population from Ceará (Juazeiro 2011), a block of telomeric sequences was observed in the short arm of the B chromosome. This block is larger than those found in other populations from Ceará, but is smaller than in populations from Pernambuco and Frecheirinha (Fig. 4m).

FISH analysis using the $\mathrm{B}$ chromosome probe obtained from 1 individual from Gravatá (PE) identified 3 patterns of signal distribution in the $\mathrm{B}$ chromosomes, depending on the population. The $\mathrm{B}$ chromosome morphotypes were named according to the labeling pattern as follows: B1, with signals distributed over the entire B chromosome, in individuals from Lagoa do Carro (PE), Gravatá (PE), Juazeiro 2011 and 2007 (CE), and Frecheirinha (CE) (Fig. 4q, s, u, v, x); B2, with more evident signals in the pericentromeric and distal regions of the $\mathrm{B}$ chromosome, in individuals from Bezerros (PE) (Fig. 4r); and $\mathrm{B} 3$, with distinct signals in the distal half of the long arm of the $\mathrm{B}$ chromosome, as noticed in the populations from Sapó (CE) and Sobral (CE) (Fig. 4t, w).

\section{Discussion}

Data on the occurrence of B chromosomes in Pernambuco and Ceará states showed a considerable variation between the populations. This element is largely geographically distributed in $X$. $d$. angulatus considering the distance between populations, reaching approximately $900 \mathrm{~km}$ between Gravatá (PE) and Sapó (CE). Another interesting aspect is the presence of the $\mathrm{B}$ chromosome in isolated populations (as is the case of Caruaru, $\mathrm{PE}$ ), where individuals were collected in remnants of moist forests of Caatinga enclaves [Machado et al., 2014]. A similar scenario with local invasion of $\mathrm{B}$ chromosomes in distinct populations was previously reported in the grasshopper E. plorans [Camacho et al., 2015].

Here, we conducted a broader analysis including more populations than the previously performed study by Machado et al. [2014], but we detected no significant difference for B chromosome prevalence regarding the biome in which $X . d$. angulatus is distributed. The correlation between habitat and prevalence of $\mathrm{B}$ chromosomes in X. $d$. angulatus was previously analyzed by Machado et al. [2014], and they also did not find any relationship be-

B Chromosome Variants in the Grasshopper X. d. angulatus tween these factors. According to Camacho et al. [2000], interpopulational differences in the frequency of B chromosomes depend on selective factors (such as ecologic tolerance of polymorphism carriers), historical events (such as number of generations existing since the emergence of the extra element as well as its transmission), and random events (such as genetic drift).

Measurements performed in B chromosomes from Pernambuco and Ceará populations suggested that there are 2 variants of the $\mathrm{B}$ chromosome in $X$. d. angulatus: the first one showing a mean $\mathrm{B} / \mathrm{X}$ ratio of 0.8 , and the second one presenting a mean ratio of 0.69 . Variability for $\mathrm{B}$ chromosome size could arise through amplification or loss of repetitive DNA sequences, which are frequently present in these elements [Houben et al., 2013, 2014]. The study carried out by Loreto et al. [2008] where amplification of heterochromatin was suggested in B chromosomes of populations from Pernambuco gives additional support to our data. Differences in the distribution pattern of C-bands in B chromosomes attest the occurrence of amplification, as the latter presented interstitial bands whereas the remaining chromosomes did not show bands at this position. Heterochromatin amplification is apparently a mechanism of B chromosome differentiation in $X . d$. angulatus, which is also supported by differences in chromosome lengths. Furthermore, these differences could be the consequence of the process of polymorphism regeneration and consequent accumulation, preventing elimination from the genome [Camacho et al., 2000], as suggested for other species harboring variable morphotypes of B chromosomes [Warchalowska-Sliwa et al., 2001; Teruel et al., 2009a].

Mapping of $\mathrm{C}_{0} \mathrm{t}-\mathrm{DNA}$ and telomere repeats at the population level gave clues about the B chromosome origin and repetitive DNA accumulation. The fact that repetitive DNAs are shared between the pericentromeric region of $\mathrm{A}$ and $\mathrm{B}$ chromosomes, as revealed by $\mathrm{C}_{0} \mathrm{t}$-DNA hybridization, points to an intraspecific origin for the $\mathrm{B}$ chromosome. Moreover, hybridization of this probe in different populations indicates conservation of at least part of the repetitive DNAs at the intraspecific level and suggests a common ancestral origin of the $\mathrm{B}$ chromosome in all populations. An intraspecific origin of the B chromosomes was suggested by mapping of $\mathrm{C}_{0} \mathrm{t}$-DNA probe in the beetle Dichotomius geminatus [Cabral-de-Mello et al., 2010]. In fact, the intraspecific origin of B chromosomes is common, and it has also been described in grasshoppers [Loreto et al., 2008; Bueno et al., 2013].

The variation in the size of the hybridization signals of the telomeric probe reinforces the idea of variability in B

Cytogenet Genome Res 2017;152:213-221 
chromosome arms, at least for accumulation/elimination of repeats. The larger signals of telomeric DNA are predominant in populations from Pernambuco and may be related to the increase of $\mathrm{B}$ chromosome size noticed in these populations. Another example concerning the presence of additional telomeric sequences in $\mathrm{B}$ chromosomes has been reported in the plant Tradescantia virginiana, where they emerged by small duplications or subterminal inversions. In addition, it has been suggested that the B chromosome originated by excision of the distal region of an A chromosome [Golczyk, 2011].

The ancestral B chromosome of $X$. $d$. angulatus probably had a reduced size and contained elements such as a centromere and telomeres, and repetitive DNA that was amplified during evolution. In rye, Secale cereale, terminal and pericentromeric sequences of B chromosomes were mapped and new variants were detected, and the pericentromeric region was probably involved in the formation of these variants [Marques et al., 2012]. An origin from centromeric segments has been reported in the literature for B microchromosomes, which might be formed from centric fragments derived from structural rearrangements [Camacho et al., 2000]. In mammals, species with acrocentric chromosomes are more likely to possess B chromosomes [Palestis et al., 2004]; further, occurrence of robertsonian translocations might favor the emergence of proto-B chromosomes in these organisms [BanaeiMoghaddam et al., 2015].

Through FISH mapping with a microdissected B chromosome probe, it was possible to demonstrate the presence of 3 different $B$ chromosome morphotypes, and not only 2 as previously identified by conventional analysis and chromosome measurements. B chromosome variants have also been identified in other grasshopper species, e.g., in P. s. sapporensis, in which 7 different B chromosome morphotypes have been reported, which differ with regard to C-band pattern and morphology [Warchalowska-Sliwa et al., 2001], and in E. plorans, in which more than $50 \mathrm{~B}$ chromosome variants were described on the basis of size, morphology, and C-band pattern [Henriques-Gil et al., 1984; Bakkali and Camacho, 2004; Abdelaziz et al., 2007].

The high mutation rate and accumulation of supernumerary elements [Abdelaziz et al., 2007] are factors that guarantee emergence of variants and morphotypes, besides avoiding their elimination from the genome of individuals. The ancestral B chromosome in X. $d$. angulatus probably underwent amplification/deletion of sequences and rearrangements, such as inversions, which contributed to the emergence of different morphotypes. These rearrangements may have given rise to the $\mathrm{B} 3$ chromosome, which exhibits homology with the B1 chromosome in its distal region. The mapping of the microdissected $\mathrm{B}$ chromosome probe also reinforces the ancestral origin of this element that experienced posterior modifications.

According to the FISH mapping of $18 \mathrm{~S}$ rDNA and Cbanding patterns, a possible autosomal origin for the $X$. d. angulatus $\mathrm{B}$ chromosome had been proposed [Loreto et al., 2008; Machado et al., 2014]. However, our data point to a pericentromeric origin. In this view, autosomal or even X-chromosomal centric fragments could provide the elements required for the $\mathrm{B}$ chromosome origin. For the latter, regions between the centromere and proximal blocks enriched with highly and moderately repetitive DNA ( $\mathrm{C}_{0} \mathrm{t}$ fraction) could result in the initial regions for the origin of the $\mathrm{B}$ chromosome, which subsequently underwent repetitive DNA amplification and rearrangements (inversion for B3, for example). Future studies focusing on novel molecular technologies and bioinformatics tools will be necessary in order to determine the specific composition of the $\mathrm{B}$ chromosomes, which could help to corroborate this hypothesis.

\section{Acknowledgements}

The authors would like to thank Dr. Carlos Carbonell (University of Montevideo, Uruguay) for taxonomic identification of species. We are grateful to Cirlene Maria da Silva for technical support and to Luiz Cipriano da Silva Neto for image enhancement. This study was developed at the Universidade Federal de Pernambuco (UFPE) and Universidade Estadual Paulista (Unesp) and funded by Fundação de Amparo à Ciência e Tecnologia de Pernambuco (FACEPE) and Fundação de Amparo à Pesquisa do Estado de São Paulo (FAPESP).

\section{Statement of Ethics}

The authors have no ethical conflicts to disclose.

\section{Disclosure Statement}

The authors declare no conflicts of interest.
Bernardino et al. 


\section{References}

Abdelaziz M, Teruel M, Chobanov D, Camacho JPM, Cabrero J: Physical mapping of rDNA and satDNA in A and B chromosomes of the grasshopper Eyprepocnemis plorans from a Greek population. Cytogenet Genome Res 119:143-146 (2007).

Bakkali M, Camacho JPM: The B chromosome polymorphism of the grasshopper Eyprepocnemis plorans in North Africa: III. Mutation rate of $\mathrm{B}$ chromosomes. Heredity 92: 428-433 (2004).

Banaei-Moghaddam AM, Meier K, KarimiAshtiyani R, Houben A: Formation and expression of pseudogenes on the B chromosome of rye. Plant Cell 25:2536-2544 (2013).

Banaei-Moghaddam AM, Martis MM, Macas J, Gundlach H, Himmelbach A, et al: Genes on B chromosomes: old questions revisited with new tools. Biochim Biophys Acta 1849:64-70 (2015).

Bidau CJ, Martí DA: B chromosomes and Robertsonian fusions of Dichroplus pratensis (Acrididae): intraspecific support for the centromeric drive theory. Cytogenet Genome Res 106:347-350 (2004).

Bueno D, Palacios-Gimenez OM, Cabral-de-Mello DC: Chromosomal mapping of repetitive DNAs in the grasshopper Abracris flavolineata reveal possible ancestry of the $\mathrm{B}$ chromosome and $\mathrm{H} 3$ histone spreading. PLoS One 8:e66532 (2013).

Bugrov AG, Karamysheva TV, Rubtsov DN, Andreenkova OV, Rubtsov NB: Comparative FISH analysis of distribution of $\mathrm{B}$ chromosome repetitive DNA in A and B chromosomes in two subspecies of Podisma sapporensis (Orthoptera, Acrididae). Cytogenet Genome Res 106:284-288 (2004).

Cabral-de-Mello DC, Moura RC, Martins C: Chromosomal mapping of repetitive DNAs in the beetle Dichotomius geminatus provides the first evidence for an association of $5 \mathrm{~S}$ rRNA and histone $\mathrm{H} 3$ genes in insects, and repetitive DNA similarity between the $\mathrm{B}$ chromosome and A complement. Heredity 104: 393-400 (2010).

Cabrero J, Viseras E, Camacho JPM: The B-chromosomes of Locusta migratoria. I. Detection of negative correlation between mean chiasma frequency and the rate of accumulation of the B's; a reanalysis of the available data about the transmission of these B chromosomes. Genetica 64:155-164 (1984).

Cabrero J, Bugrov A, Warchałowska-Sliwa E, López-León MD, Perfectti F, Camacho JP: Comparative FISH analysis in five species of eyprepocnemidine grasshoppers. Heredity 90:377-381 (2003).
Camacho JPM: B chromosomes, in Gregory TR (ed): The Evolution of the Genome, pp 223286 (Elsevier, San Diego 2005).

Camacho JPM, Sharbel TF, Beukeboom LW: Bchromosome evolution. Philos Trans R Soc Lond B Biol Sci 355:163-178 (2000).

Camacho JPM, Shaw MW, Cabrero J, Bakkali M, Ruíz-Estévez M, et al: Transient microgeographic clines during $\mathrm{B}$ chromosome invasion. Am Nat 186:675-681 (2015).

Golczyk H: Structural heterozygosity, duplication of telomeric (TTTAGGG) $)_{n}$ clusters and B chromosome architecture in Tradescantia virginiana L. Cytogenet Genome Res 134: 234-242 (2011).

Henriques-Gil N, Santos JL, Arana P: Evolution of a complex B-chromosome polymorphism in the grasshopper Eyprepocnemis plorans. Chromosoma 89:290-293 (1984).

Hewitt GM: Animal Cytogenetics 3. Insecta 1. Orthoptera: Grasshoppers and Crickets (Gebrüder Borntraeger, Berlin 1979).

Houben A, Banaei-Moghaddam AM, Klemme S: Biology and evolution of $\mathrm{B}$ chromosomes, in Greilhuber J, Dolezel J, Wendel JF (eds): Plant Genome Diversity, vol 2, pp 149-165 (Springer, Wien 2013).

Houben A, Banaei-Moghaddam AM, Klemme S, Timmis JN: Evolution and biology of supernumerary B chromosomes. Cell Mol Life Sci 71:467-478 (2014).

Ijdo JW, Baldini A, Ward DC, Reeders ST, Wells RA: Origin of human chromosome 2: an ancestral telomere-telomere fusion. Proc Natl Acad Sci USA 88:9051-9055 (1991).

López-León MD, Neves N, Schwarzacher T, Heslop-Harrison JS, Hewitt GM, Camacho JP: Possible origin of a B chromosome deduced from its DNA composition using double FISH technique. Chromosome Res 2:87-92 (1994).

Loreto V, Cabrero J, López-León MD, Camacho JPM, Souza MJ: Possible autosomal origin of macro B chromosomes in two grasshopper species. Chromosome Res 16:233-241 (2008).

Machado CB, Silva-Neto LC, Loreto V, Souza MJ: $\mathrm{B}$ chromosome prevalence and physical mapping of $18 \mathrm{~S}$ rDNA and $\mathrm{H} 4$ histone sites in the grasshopper Xyleus discoideus angulatus (Romaleidae). Genet Mol Res 13:7052-7060 (2014).

Marques A, Klemme S, Guerra M, Houben A: Cytomolecular characterization of de novo formed rye B chromosome variants. Mol Cytogenet 5:34 (2012).

Palestis BG, Trivers R, Burt A, Jones RN: The distribution of B chromosomes across species. Cytogenet Genome Res 106:151-158 (2004).

Pinkel D, Landegent J, Collins C, Fuscoe J, Segraves $\mathrm{R}$, et al: Fluorescence in situ hybridization with human chromosome-specific libraries: detection of trisomy 21 and translocations of chromosome 4. Proc Natl Acad Sci USA 85:9138-9142 (1986).
Ruíz-Estévez M, López-León MD, Cabrero J, Camacho JPM: B-chromosome ribosomal DNA is functional in the grasshopper Eyprepocnemis plorans. PLoS One 7:e36600 (2012).

Ruíz-Estévez M, López-León MD, Cabrero J, Camacho JPM: Ribosomal DNA is active in different $B$ chromosome variants of the grasshopper Eyprepocnemis plorans. Genetica 141: 337-345 (2013).

Souza MJ, Kido LMH: Variability of constitutive heterochromatin in karyotypes of representatives of the family Romaleidae (Orthoptera). Braz J Genet 18:517-520 (1995).

Souza MJ, Silva-Filha MHN: Effects of extra chromosome segments on chiasma distribution in Xyleus angulatus (Orthoptera, Romaleidae). Braz J Genet 16:23-33 (1993).

Teruel M, Cabrero J, Perfectti F, Acosta MJ, Sánchez A, Camacho JPM: Microdissection and chromosome painting of $\mathrm{X}$ and $\mathrm{B}$ chromosomes in the grasshopper Eyprepocnemis plorans. Cytogenet Genome Res 125:286-291 (2009a).

Teruel M, Cabrero J, Montiel EE, Acosta MJ, Sánchez A, Camacho JPM: Microdissection and chromosome painting of $\mathrm{X}$ and $\mathrm{B}$ chromosomes in Locusta migratoria. Chromosome Res 17:11-18 (2009b).

Trifonov VA, Dementyeva PV, Larkin DM, O'Brien PC, Perelman PL, et al: Transcription of a protein-coding gene on $\mathrm{B}$ chromosomes of the Siberian roe deer (Capreolus pygargus). BMC Biol 11:90 (2013).

Valente GT, Conte MA, Fantinatti BEA, Cabralde-Mello DC, Carvalho RF, et al: Origin and evolution of B chromosomes in the cichlid fish Astatotilapia latifasciata based on integrated genomic analyses. Mol Biol Evol 31: 2061-2072 (2014).

Vilardi JC: Isocromosomas B e irregularidades meioticas en dos espécies de Euplectrotettix (Orthoptera: Acrididae). Mendeliana 7:125137 (1986a).

Vilardi JC: Parallel polymorphisms for interstitial C-bands and B-chromosomes in Zoniopoda tarsata (Orthoptera-Romaleidae). Caryologia 39:365-380 (1986b).

Warchałowska-Sliwa E, Bugrov AG, Tatsuta H, Akimoto S: B chromosomes, translocation between $\mathrm{B}$ and autosomes, and C-heterochromatin polymorphism of the grasshopper $\mathrm{Po}$ disma sapporensis Shir. (Orthoptera, Acrididae) in Hokkaido, northern Japan. Folia Biol (Krakow) 49:63-75 (2001).

Zwick MS, Hanson RE, Islam-Faridi MN, Stelly DM, Wing RA, et al: A rapid procedure for the isolation of $\mathrm{C}_{0} \mathrm{t}-1 \mathrm{DNA}$ from plants. Genome 40:138-142 (1997).
B Chromosome Variants in the

Grasshopper X. d. angulatus
Cytogenet Genome Res 2017;152:213-221 DOI: $10.1159 / 000480036$ 